\title{
Relapse with multibacillary leprosy caused by rifampicin sensitive organisms following paucibacillary multidrug therapy
}

\author{
D. J. SOARES*, K. NEUPANE* \& W. J. BRITTON† \\ * Anandaban Leprosy Hospital, PO Box 151, Kathmandu, Nepal; \\ and $\dagger$ Department of Medicine, University of Sydney, NSW 2006, \\ Australia
}

\section{Accepted for publication 6 January 1995}

\begin{abstract}
Summary Many leprosy patients treated with multidrug therapy (MDT) had previously received dapsone (DDS) monotherapy for many years. We report here 2 such patients treated with modified paucibacillary MDT composed of rifampicin and DDS who subsequently relapsed with multibacillary leprosy 5 and 6 years after release from treatment. Isolates of Mycobacterium leprae from both patients were resistant to DDS but sensitive to rif ampicin, suggesting that the relapses were caused by rifampicin sensitive 'persister' organisms. The implications of this for surveillance of patients released from treatment (RFT) and the management of relapsed patients is discussed.
\end{abstract}

\section{Introduction}

The introduction of $\mathrm{MDT}^{1}$ has been a major advance in the treatment of leprosy. The implementation of MDT was stimulated by the increasing prevalence of secondary DDS resistance in previously-treated patients and the emergence of primary DDS resistance, caused by the transmission of drug resistant organisms. Nordeen ${ }^{2}$ has estimated the relapse rates to be $0 \cdot 12 \%$ per year for $\mathrm{PB}$ cases and $0 \cdot 22 \%$ per year for $\mathrm{MB}$ cases in groups of previously-treated and untreated patients. However, relapse with lepromatous leprosy may only occur 5-10 years after the cessation of either monotherapy with dapsona $^{3}$ or various forms of MDT. ${ }^{4}$ Therefore such cases may only become apparent years after the implementation of MDT, and it is important to determine patterns of drug sensitivity of responsible Mycobacterium leprae bacilli.

\section{Case report 1}

A 20-year-old female first presented in 1969 with ulceration under the second metatarsal head of the right foot. There was sensory loss on both soles and both lateral popliteal nerves were readily palpable. Skin ulceration was present on the hands. A single 
Table 1

\begin{tabular}{lcc}
\hline & Case 1 & Case 2 \\
\hline Initial presentation & 1969 & 1964 \\
Initial smear & $1 \% 0+$ & $1 \cdot 5+$ \\
Low dose DDS & Yes & Yes \\
Modified PB-MDT & 1983 & 1983 \\
Relapse year & 1989 & 1990 \\
Relapse smear & $5 \cdot 0+$ & $4 \cdot 5+$ \\
PGL1-Ab & 0.690 & $0 \cdot 345$ \\
DDS resistance & Low $(0.0001 \%)$ & High $(0.01 \%)$ \\
Rifampicin & Sensitive & Sensitive \\
& & \\
\hline
\end{tabular}

anaesthetic patch with a shiny atrophic surface was present on the right shin. Initial skin smears from the left and right back were positive, with a bacillary index (BI) of $1+$. Skin smears were negative elsewhere. In accordance with the 1969 practice, she was started on low dose DDS (25 mg weekly), which was then gradually increased to $50 \mathrm{mg}$ twice a week for 4 years, and then $100 \mathrm{mg}$ twice a week for 1 year. Daily DDS was then commenced at $25 \mathrm{mg}$ per day, increasing to $100 \mathrm{mg}$ per day by 1979,10 years after the initial diagnosis. DDS was continued at this dosage until 1983. Clinical examination then revealed no skin lesions of thickened palpable peripheral nerves; however, there was extensive chronic neuropathic damage with right ulnar and median nerve palsy, left ulnar nerve palsy, clawing of the left toes and anaesthesia of both feet. Repeated skin smears since 1969 had been negative. In 1983, when MDT was introduced, the patient was reassessed. She was considered to have inactive borderline-tuberculoid leprosy and was started on modified PB-MDT. This consisted of rifampicin $600 \mathrm{mg}$ on 2 consecutive days per month and dapsone $100 \mathrm{mg}$ daily for 6 months from October 1983 to March 1984. She was then released from treatment and on subsequent reviews in 1987 and 1988 was well, with negative skin smears.

In April 1989, new erythematous raised well-defined skin lesions developed on her face, chest and shoulders (see Table 1 for results). Skin smears from the lesions were strongly positive with BI 5+. Histopathology of the lesion revealed borderline lepromatous leprosy with a BI of $4+$ and a morphological index (MI) of $2 \cdot 0 \%$.

MB-MDT was commenced with monthly rif ampicin $600 \mathrm{mg}$ and clofazimine $300 \mathrm{mg}$ and daily DDS $100 \mathrm{mg}$ and clofazimine $50 \mathrm{mg}$. After 61 regular doses there was resolution of the skin lesions, and a fall in the mean BI from $4 \cdot 5+$ to $0 \cdot 0+$. The patient has now been RFT.

\section{Case report 2}

A 31-year-old male first presented in December 1964 with an anaesthetic patch on his right knee but no peripheral nerve damage. Skin smears from routine sites were positive with a mean BI of $1.5+$. He commenced low dose DDS therapy, $25 \mathrm{mg}$ per week, increasing to $50 \mathrm{mg}$ per week. After 3 years of irregular therapy his skin smears were still positive with a mean BI of $1+$. After 2 further years of DDS therapy at $25 \mathrm{mg}$ twice a week, the skin smears became negative. He continued DDS $50 \mathrm{mg}$ daily for the next 13 
years; however, he was very irregular, missing at least 3 years of therapy. Over this period the skin smears remained negative, there were no signs of active disease and he was subsequently released from treatment in December 1982. In September 1983 following the introduction of MDT he was started on a course of modified PB-MDT. Over 6 months he received supervised domiciliary rifampicin $600 \mathrm{mg}$ twice a month and DDS $100 \mathrm{mg}$ daily. He remained asymptomatic with negative skin smears and was released from treatment.

In September 1989, 6 years later, there were no clinical signs of activity on clinical review, but 12 months later in October 1990, he re-presented with ulceration of both hands. Examination revealed diffuse cutaneous infiltration, enlarged bilateral ulnar and lateral popliteal nerves and anaesthesia of both hands with secondary ulceration. Skin smears were positive with a mean BI of $4 \cdot 5+$ and an MI of $4+$ (see Table 1 for results).

Skin biopsy was performed for mouse footpad inoculation and $M$. leprae was isolated after 7 months growth. The isolate was resistant to high dose DDS $(0 \cdot 01 \%)$ with growth in $3 / 10$ footpads and were fully sensitive to rifampicin with no growth occurring in 10/10 footpads of mice receiving $0.05 \%$ rifampicin by gastric lavage.

The patient was recommenced on MB-MDT with rifampicin $600 \mathrm{mg}$ and clofazimine $300 \mathrm{mg}$ once per month and DDS $100 \mathrm{mg}$ and clof azimine $50 \mathrm{mg}$ daily. In addition, ofloxacin $400 \mathrm{mg}$ daily was given for 14 days. After completing 26 doses of MDT, the skin lesions had resolved, and the mean BI had fallen from $4 \cdot 5+$ to $2 \cdot 0+$.

\section{Discussion}

Relapse after MDT has been previously observed within leprosy control programmes in Nepal. van Brake et al. ${ }^{5}$ documented relapse rates of $7 \cdot 3$ per 1000 per annum in PB and 4 per 1000 per annum in MB leprosy. A cause of relapse was the misclassification of MB leprosy patients as $\mathrm{PB}$, resulting in inadequate chemotherapy. Both these patients were considered to have treated BT leprosy and so were given modified PB-MDT which included 12 doses of rifampicin $600 \mathrm{mg}$ over 6 months. The initial WHO-MDT recommendations included skin-smear positive BT in the PB treatment group and Case 1 may have been an example of this category. Case 2, however, was probably BL leprosy when seen in 1964 because skin smears from routine sites were positive.

Under the revised WHO guidelines both would now be given MB-MDT, because all patients with any positive skin smear, regardless of classification, are considered as multibacillary leprosy sufferers. ${ }^{6}$ There have been few reports of drug sensitivity patterns in patients relapsing after MDT. The DDS resistance of both these isolates was due to the prolonged low dose DDS therapy the patients received in the 1960s and 1970s. However, despite receiving rifampicin for 6 months, both isolates were fully rif ampicin sensitive. As the bacillary load at the time PB-MDT was administered would have been very low, it is unlikely that these patients would develop rifampicin resistance. This suggests that relapse was due to proliferation of the few 'persister' organisms which had been metabolically dormant during the period of PB-MDT and had not developed rifampicin resistance.

The presence of 'persisters' after DDS monotherapy is well documented. More pertinently, during the THELEP drug trials, persisting $M$. leprae bacilli were detected in $9 \%$ of all patients, irrespective of the regimen or duration of MDT. Recently relapse 
with fully sensitive organisms was reported in a patient 52 months after receiving an intensive course of MDT including daily rifampicin for 24 months. ${ }^{7}$ Drug-sensitive persister organisms were implicated as the cause. This contrasts with the pattern of relapse observed after rifampicin monotherapy for active DDS-resistant leprosy when $22 / 39$ of the isolates from MB relapses were rifampicin resistant. ${ }^{8}$

These cases highlight a number of issues concerning the implementation of MDT. First, all patients with past or present evidence of skin smear positivity should be assigned to MB-MDT. Second, even in the presence of pre-existing DDS resistance, the organisms responsible for multibacillary relapse may retain sensitivity to rifampicin. Third, relapse with rif ampicin sensitive persister organisms may occur more than 5 years after release from treatment. This emphasizes the need for surveillance of MB patients up to 10 years after the completion of MDT. This will ensure that any patients with MB relapse are promptly treated and do not act as a source for the continuing spread of leprosy in the community.

\section{References}

1 World Health Organisation. Chemotherapy of leprosy for control programmes. Technical Report Series. 1982; 675.

${ }^{2}$ Nordeen SK. Leprosy control through multidrug therapy. Bull World Health Organ, 1991; 69: $263-9$.

${ }^{3}$ Water MFR, Rees RJW, Laing ABG, Khoo Kah Fah, Meade TW, Parikshak M, North NRS. The rate of relapse in lepromatous leprosy following completion of twenty years of supervised sulphone therapy. Lepr Rev, 1986, 57: 101-9.

${ }^{4}$ Becx-Bleumink M. Relapses among leprosy patients treated with multidrug therapy. Experience in the Leprosy Control Program of the All African Leprosy and Rehabilitation Training Centre (ALERT) in Ethiopia: practical difficulties with diagnosing relapses; operational procedure and criteria for diagnosing relapse. Int J Lepr, 1992; 60: 421-35.

5 van Brakel WH, Kist P, Nobles, O'Toolel. Relapses after multidrug therapy for leprosy: a preliminary report of 2 cases in Wed Nepal. Lepr Rev, 1989; 60: 4550.

6 World Health Organisation Expert Committee on Leprosy. Technical Report Series. 1988; 768.

7 Constant-Desportes M, Guelpa-Lauras C, Carolina JC, Leoture A, Cerosset JH, Sansarricq H. A case of relapse with drug susceptible $M$. leprae after Multidrug therapy. Int J Lepr, 1991; 59: 242-7.

${ }^{8}$ Grosset JH, Guelpa-Lauras CC, Bobin P, et al. Study of 39 documented relapses of multibacillary leprosy after treatment with rifampicin. Int $J$ Lepr, 1989; 57: 607-12. 